\title{
Estrogen, progesterone, and human epidermal growth factor receptor 2 discordance between primary and metastatic breast cancer
}

\author{
Vincent Walter ${ }^{1} \cdot$ Chiara Fischer $^{2,3} \cdot$ Thomas M. Deutsch $^{2,3} \cdot$ Catherine Ersing $^{1} \cdot$ Juliane Nees $^{2} \cdot$ Florian Schütz $^{2}$. \\ Carlo Fremd $^{3} \cdot$ Eva-Maria Grischke $^{1} \cdot$ Peter Sinn $^{5} \cdot$ Sara Y. Brucker $^{1} \cdot$ Andreas Schneeweiss $^{3,4}$. Andreas D. Hartkopf ${ }^{1}$. \\ Markus Wallwiener ${ }^{2}$ (D)
}

Received: 22 December 2019 / Accepted: 1 June 2020 / Published online: 1 July 2020

(c) The Author(s) 2020

\begin{abstract}
Background The estrogen receptor (ER), progesterone receptor (PR), and human epidermal growth factor receptor 2 (HER2) statuses are frequently discordant between the primary tumor and metastatic lesions in metastatic breast cancer. This can have important therapeutic implications.

Patients and methods In all, 541 patients with available receptor statuses from both primary tumor and metastatic lesion treated at Heidelberg and Tuebingen University Hospitals between 1982 and 2018 were included.

Results Statistically significant discordance rates of $14 \%$ and $32 \%$ were found for ER and PR. HER 2 status was statistically insignificantly discordant in $15 \%$ of patients. Gain in HER2 positivity was associated with an improved overall survival, whereas loss of HR positivity was associated with worse overall survival. Antiendocrine treatment differed in $20 \%$ of cases before and after biopsy and HER2-directed treatment in 14\% of cases.

Conclusions Receptor statuses are discordant between primary tumor and metastasis in a considerable fraction of patients with metastatic breast cancer. Next to a highly presumed predictive value with respect to efficacy of endocrine and HER2targeted therapy, discordance seems to provide prognostically relevant information. Where feasible, metastatic lesions should be biopsied in accordance with current guidelines.
\end{abstract}

Keywords Metastatic breast cancer · Receptor status discordance $\cdot$ Distant metastasis $\cdot$ Estrogen receptor (ER) Progesterone receptor (PR) · Human epidermal growth factor receptor 2 (HER2)

\section{Introduction}

With 2.1 million new diagnoses predicted for 2018, breast cancer represents the most prevalent type of cancer in women worldwide [1]. Despite new therapeutic agents and improved survival, (metastatic) breast cancer is considered a leading cause of death among women, with about 700,000 deaths in 2018 [1-3]. Inevitably, therefore, the tumor burden must be closely monitored and targeted systemic therapy

Vincent Walter and Chiara Fischer have shared first author.

Electronic supplementary material The online version of this article (https://doi.org/10.1007/s10549-020-05746-8) contains supplementary material, which is available to authorized users.

Markus Wallwiener

Markus.Wallwiener@med.uni-heidelberg.de

Extended author information available on the last page of the article (chemotherapy, endocrine therapy, targeted therapy, and biological therapy) or local therapy (surgery and radiation therapy) adjusted.

The estrogen receptor (ER), progesterone receptor (PR), and human epidermal growth factor receptor 2 (HER2) statuses of primary breast cancer tissue are used clinically to approximate biological subtypes, to predict outcome, and to guide therapy decisions, especially for endocrine and HER2targeted regimens $[4,5]$. However, numerous studies have shown substantial discordance rates in ER, PR, and HER2 receptor profiles between primary and metastatic tumors. Based on a meta-analysis of 39 studies, Schrijver et al. [6] reported conversion rates of $19.3 \%$ for ER, $30.9 \%$ for PR, and $10.3 \%$ for HER2, respectively. Yeung et al. [7] showed similar findings in a meta-analysis of 47 studies including 3,384 matched primary and metastatic breast cancer cases with median discordance rates of ER, PR, and HER2-expression of $14 \%, 21 \%$, and $10 \%$, respectively. Furthermore, loss 
of receptor positivity is associated with poorer prognosis [8, 9]. Indeed, the meta-analysis by Schrijver et al. showed that therapy was changed due to receptor discordance in $14 \%$ for ER, $62 \%$ for PR, and $67 \%$ for HER2, respectively, assuming that patients gaining hormone receptor positivity qualify for endocrine therapy and those gaining HER2 positivity are eligible for HER2-directed therapy [6].

Given the broad evidence for receptor status conversion during tumor progression, NCCN, ESMO, EGTM, and ASCO guidelines congruently recommend re-testing hormone receptors for metastatic lesions where feasible [4, 10-12]. However, it is not known whether tissue sampling of metastatic sites has any significant effect on patient survival or quality of life [13, 14] and whether the biology of the primary or the metastatic lesion(s) should guide therapeutic decisions [11].

Our study retrospectively compared ER, PR, and HER2 receptor profiles in biopsies of primary breast cancer and corresponding metastatic lesions in a large study population to assess individual changes throughout tumor progression and location-specific discordance rates.

\section{Patients and methods}

\section{Study design and samples}

This study includes women aged 18 or older with metastatic breast cancer where expression level data were available for at least one of the receptors-estrogen, progesterone, or human epidermal growth factor receptor 2 -for the primary tumor and corresponding metastatic lesion. If more than one metastatic lesion was available, only the lesion first biopsied was evaluated. Patients were enrolled between 1982 and 2018 at the National Centre for Tumor Diseases (NCT) in Heidelberg, the Department of Obstetrics and Gynecology at the University Hospital Heidelberg, and the University Hospital Tuebingen, Germany. This study was approved by the ethics committee of the medical faculty of Heidelberg (S-295/2009) and Tuebingen (270/2014A) University.

\section{ER, PR, and HER2 assessment}

ER, PR, and HER2 receptor status as well as histopathological characteristics and clinical documentation were retrospectively collected from medical records. Analysis of the hormone receptor status were performed at the University Hospital Tuebingen, the University Hospital Heidelberg and in some instances at peripheral hospitals and defined as hormone receptor-positive according to local standards. The tumor was defined as hormone receptor (HR)-positive if the receptor status of either ER or PR was immunohistochemically positive. HER 2 status was assessed by immunohistochemistry (IHC) and/or fluorescent in situ hybridization
(FISH). According to ASCO guidelines, HER2 status was positive when the ISH score $(0,1+, 2+, 3+)$ was either $3+$ or the ISH score was +2 with positive fluorescence in situ hybridization (FISH) or chromogenic in situ hybridization in addition (CISH) staining [15].

Follow-up and survival status were documented until loss to follow-up or death. Data were censored at the last follow-up.

\section{Statistical analysis}

McNemar's test was used to compare paired nominal data between the primary tumor and matched metastasis of individual patients. Association of nonpaired nominal data was tested using Fisher's exact test. The median follow-up was calculated using the reverse Kaplan-Meier method. The logrank test was used to compare survival distributions. Overall survival was defined as time difference between first diagnosis of any metastasis and death. Patients in whom no event was documented or who were lost to follow-up were censored. Statistical analysis and visualization were performed using $\mathrm{R}$ version 3.5.0 with the packages ggplot 2 version 3.1.0 and survminer version 0.4.3. The significance level was set to $a<0.05$. Tests were performed in a two-sided fashion.

\section{Results}

Data from 541 patients, 324 from Heidelberg and 217 from Tuebingen, were available for analysis. In all, 105 (20\%) patients had already developed metastases at primary diagnosis. The menopausal status at primary diagnosis was available for 243 patients, 81 (33\%) of whom were premenopausal. ER status for both primary tumor and metastasis was available from 538, PR status from 536, and HER2 status from 456 patients. The primary tumor was ER-positive in 421 (78\%) patients, PR-positive in 385 (72\%), and HER2positive in $92(20 \%)$. The ER, PR, and HER2 status of the metastases was positive in $382(71 \%), 275(51 \%)$, and $102(22 \%)$ cases, respectively. The median follow-up was 58 months. A total of 291 deaths were recorded. Further patient and tumor characteristics can be found in Table 1 .

\section{Receptor status concordance}

The HR of $70(13 \%, p<0.001)$ patients differed between primary tumor and metastasis, with $13(19 \%)$ patients gaining and 57 (82\%) patients losing positivity (Table S1). Among the patients, 73 (14\%), 174 (32\%), and 68 (15\%) had discordant ER, PR, and HER2 statuses in their primary tumor and metastasis, respectively, indicating statistically significant discordance between ER and PR status, but not HER 2 status $(p<0.001, p<0.001$, and $p=0.225$, 


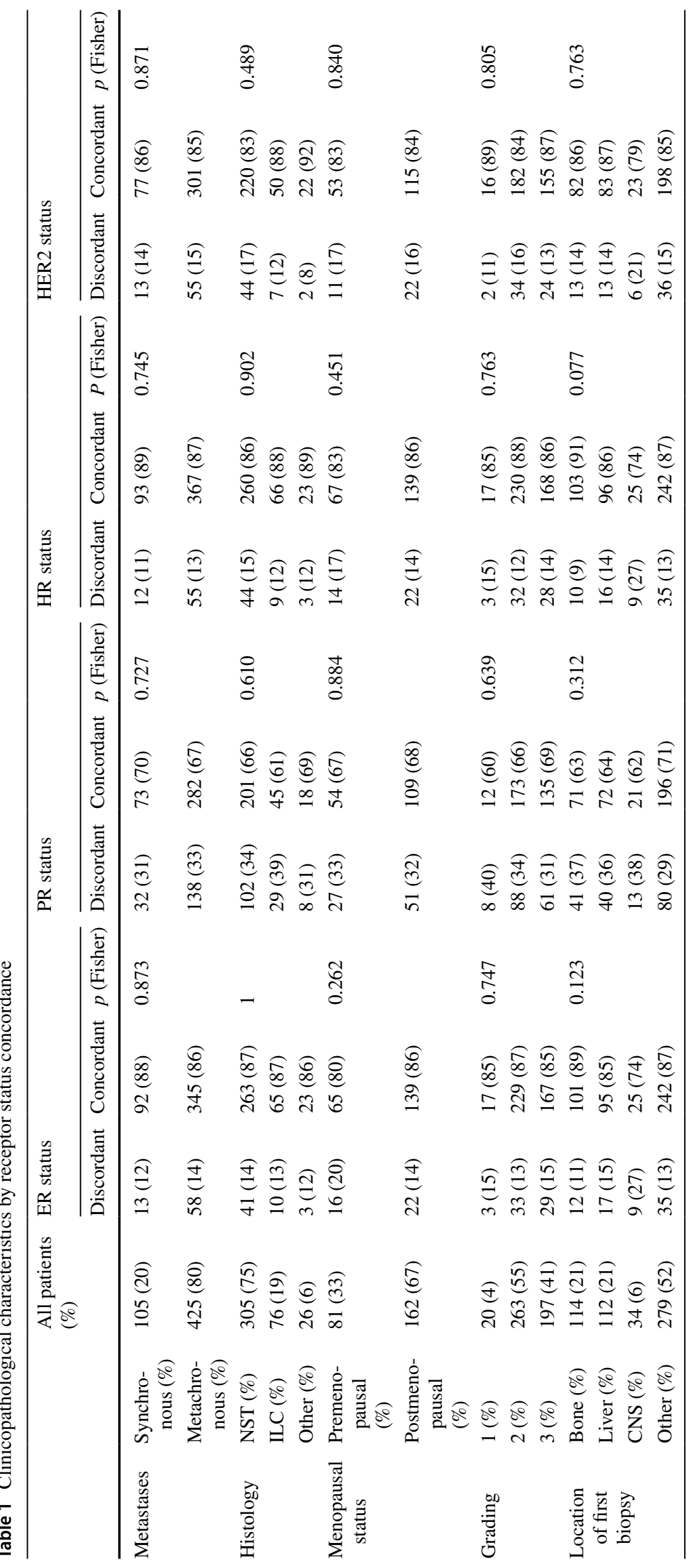


Tables S2-4). Of these discordances, 17 (23\%), 32 (18\%), and $39(57 \%)$ were gains in receptor positivity and 56 (77\%), $142(82 \%)$, and 29 (43\%) were losses of ER, PR, and HER2 positivity, respectively. The discordance was not statistically significantly different between the locations of metastatic biopsy (Table 1). Loss of HR positivity but not HER2 positivity was associated with a significantly worse OS (HR: median OS 39.3 vs. 56.2 months, $p=0.003$; HER 2 : median OS 56.2 vs. 64.5 months, $p=0.132$ ), whereas gain of HER2 but not HR positivity was associated with a significantly better OS (HER2: median OS 56.9 vs. 37.2 months, $p=0.035$; HR: median OS 39.3 vs. 26.3 months, $p=0.169$, Figs. 1 and 2).

\section{Antiendocrine and HER2-directed treatment}

Data on antiendocrine treatment and HER2-directed therapy before and after biopsy of the first metastasis as well as HR status of both primary tumor and first metastasis were available in 451 and 393 cases, respectively. Antiendocrine treatment changed in 88 (20\%, Table 2) and HER2-directed treatment in $55(14 \%$, Table 3$)$ of cases.

\section{Discussion}

The choice of targeted therapy for patients with metastatic breast cancer is guided by ER, PR, and HER2 status of the

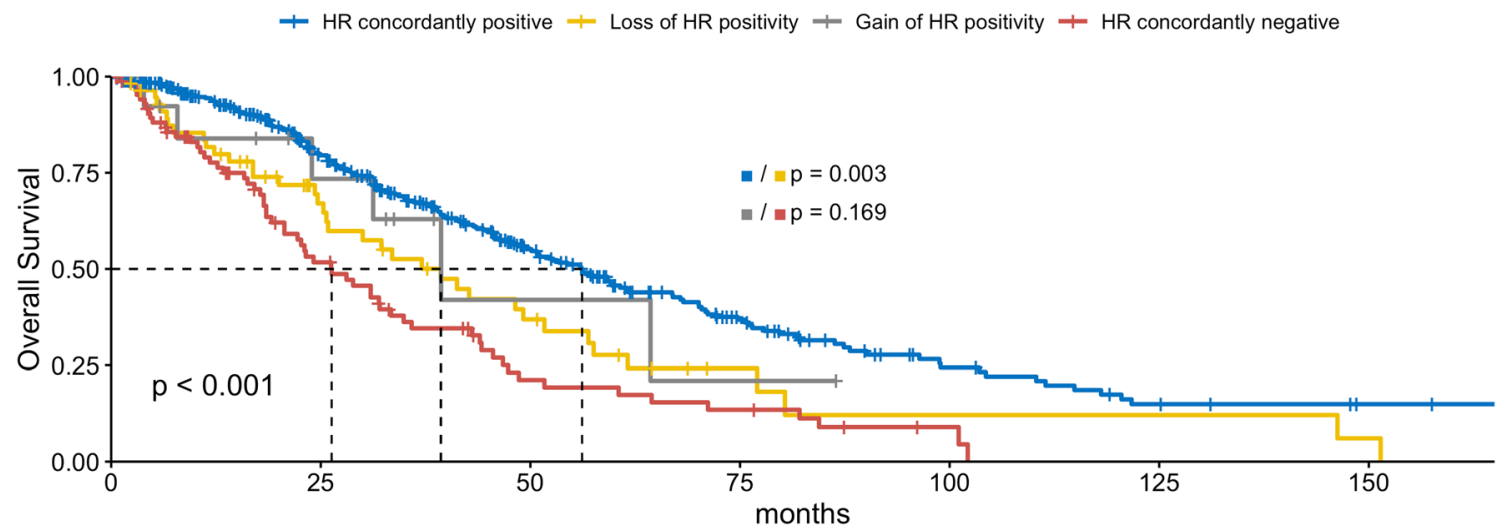

Number at risk

$\begin{array}{rr}-\quad 381 & 228 \\ -\quad 57 & 28 \\ -\quad 13 & 7 \\ -\quad 87 & 35\end{array}$

$\begin{array}{cc}228 & 112 \\ 28 & 14 \\ 7 & 2 \\ 35 & 11\end{array}$

51
4
1
7

22
2
0
2

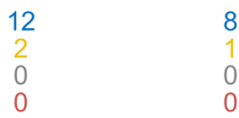

Fig. 1 Overall survival by HR status change in months

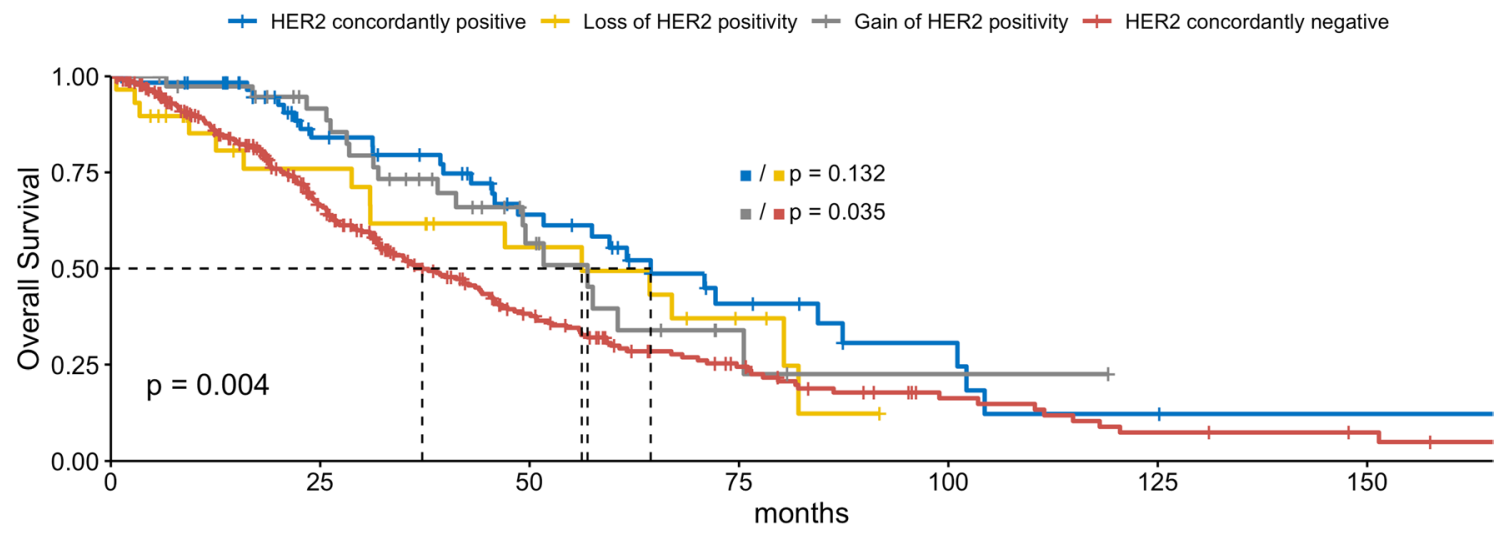

Number at risk

$\begin{array}{rr}-\quad 63 & 38 \\ -\quad 29 & 16 \\ -\quad 39 & 30 \\ -\quad 325 & 159\end{array}$

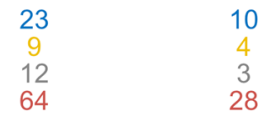

10
4
3
28

$\begin{array}{ccc}5 & 2 & 1 \\ 0 & 0 & 0 \\ 1 & 0 & 0 \\ 11 & 5 & 3\end{array}$

Fig. 2 Overall survival by HER2 status change in months 
Table 2 Antiendocrine treatment by change of hormone receptor status in metastatic biopsy

\begin{tabular}{llllll}
\hline & \multicolumn{4}{l}{ Antiendocrine treatment } \\
\cline { 3 - 6 } & $\begin{array}{l}\text { Before and } \\
\text { after biopsy }\end{array}$ & Only before biopsy & Only after biopsy & None \\
\hline \multirow{2}{*}{ HR Status } & Concordantly positive (\%) & $242(76)$ & $42(13)$ & $30(9)$ & $5(2)$ \\
& Loss of positivity (\%) & $13(29)$ & $26(58)$ & $0(0)$ & $6(13)$ \\
& Gain of positivity (\%) & $0(0)$ & $0(0)$ & $7(64)$ & $4(36)$ \\
& Concordantly negative (\%) & $0(0)$ & $0(0)$ & $1(1)$ & $75(99)$ \\
\hline
\end{tabular}

Table 3 HER2-directed therapy by change of HER2 status in metastatic biopsy

\begin{tabular}{llllll}
\hline & & \multicolumn{4}{l}{ HER2-directed therapy } \\
\cline { 3 - 5 } & & $\begin{array}{l}\text { Before and } \\
\text { after biopsy }\end{array}$ & Only before biopsy & Only after biopsy & None \\
\hline HER2 status & Concordantly positive $(\%)$ & $30(58)$ & $9(17)$ & $11(21)$ & $2(4)$ \\
& Loss of positivity (\%) & $2(10)$ & $10(50)$ & $2(10)$ & $6(30)$ \\
& Gain of positivity (\%) & $1(3)$ & $0(0)$ & $22(61)$ & $13(36)$ \\
Concordantly negative $(\%)$ & $0(0)$ & $0(0)$ & $1(0)$ & $284(100)$ \\
\hline
\end{tabular}

primary tumor, despite evidence indicating that hormone receptor status may change during tumor progression [4, $6,11]$. Discordant receptor expression between primary tumor and metastatic site is prognostic [16-18] and might be clinically relevant if changes in hormone receptor status go unnoticed. Antiendocrine or HER2-directed therapy might be ineffective, with the additional cost of side effects if the metastatic tumor loses its receptor positivity, whereas potential effective targeted therapy might be withheld if gain of receptor positivity remains undetected. However, conversion rates vary to a great extent in the literature. Furthermore, there is disagreement concerning an association of such changes with outcome and clinical implications.

In our study, we found that clinically used biomarkers were highly unstable between the primary tumor and the metastatic lesion. ER, PR, and HER2 status changed in $14 \%, 32 \%$, and $15 \%$, respectively. Although the change of HER2 status was not statistically significant, the percentage of discordant patients is clinically meaningful. These discordance rates are similar to the pooled random effects percentages of $19 \%, 31 \%$, and $10 \%$ that Schrijver et al. reported [6]. However, in contrast to previous reports [6], we were unable to see any significant difference between site-specific discordance rates.

Patients who lost HR positivity had a significantly poorer prognosis than concordantly receptor-positive patients. Gain of HER2 positivity was associated with a significantly more favorable prognosis than concordantly negative receptor status which may reflect benefit from adjustment of therapy. This finding is in line with prior studies, underlining the importance of reassessing receptor status in the metastatic setting [8, 9, 19-21].

There are several conceivable explanations for a discordant receptor status in breast tumors, including technical and analytical variability in immunohistochemical analysis, a heterogeneous tumor biology, and biological evolution.

Several studies reported varying concordance of results between the surgical specimen and core needle biopsy of ER (77.8 to 99\%), PR (69 to 97\%), and HER2 (64 to 97\%), respectively, with particular emphasis placed on a general tendency for higher discrepancies in PR status [22-27]. In addition to substantial improvement in receptor measurement accuracy, interlaboratory variation still exists in the assignment of receptor status [28, 29]. The choice of method (such as IHC and RT-PCR), the assay method (dual-antibody vs single-antibody ER assay), as well as sample processing (e.g., decalcification reduced staining intensity especially in bone metastasis) may yield to discordant results [29-31]. Moreover, the cut-off for ER/PR positivity may vary when histology results from different pathologists are compared and have changed over the last decades. Nevertheless, it is unlikely that receptor status conversion in our cohort is solely attributable to technical issues, as differences in OS depending on the ER and PR are biologically meaningful observations given the superior prognosis of hormone receptor-positive breast cancers [32].

Breast cancers are genomically and transcriptomically heterogeneous tumors [33-36]. This intratumoral heterogeneity is also observed for ER expression [16]. Additionally, different metastatic locations seem to activate different gene expression profiles within metastatic cells [37].

As tumors are heterogeneous and sequential biopsies are invasive procedures, increasing focus is being put on liquid biopsies. Here, sequential sample collection is not difficult and technological advances such as the circulating tumor cell detection or the characterization of cell-free tumor DNA in blood are promising approaches [38, 39]. With continuous 
measurement, these biomarkers could represent current systemic tumor burden, monitor evolving tumor biology in real time, assess treatment efficacy, and, thus, guide therapy more comprehensively [40-42].

In our collective, antiendocrine treatment was subject to change in $20 \%$ of patients and HER2-directed treatment in $14 \%$ of patients before and after metastasis biopsy. This is in line with previously reported fractions of $18-57 \%$ and $7-50 \%$ in other cohorts ( [43-47]). Concluding, it is clinically relevant to detect changes in receptor status in the metastatic setting in order to tailor therapeutic interventions according to present tumor manifestation.

The validity of our data is limited and should be interpreted with caution, as in some cases more than one metastasis and/or local recurrences were subjected to biopsy. Moreover, in patients where treatment was carried out in closer to home clinics, therapeutic measures recorded here were mere recommendations, the adherence to which was not recorded. Therefore, causality of metastatic receptor status change and accordingly treatment change as documented in our dataset cannot be established. Moreover, Trastuzumab only received approval for treatment of metastatic breast cancer in 2000 and for adjuvant treatment in patients with early breast cancer in 2006 in Germany. Our dataset, however, also includes patients treated before those dates, which therefore introduces another confounding variable [48].

Further limitations of our study are the retrospective design and the decentralized determination of receptor status. Thus, for some patients immunohistochemical analysis of the primary tumor and the metastasis was carried out in different laboratories. Furthermore, biopsies were collected and analyzed over a period of about 15 years, during which cut-off values for hormone receptor status were lowered. However, this approach reflects clinical reality, especially as endocrine or HER2-directed treatment was chosen due to the respective definition of ER-/PR and HER2 positivity.

\section{Conclusions}

We found that $13 \%$ and $15 \%$ of 543 patients from Heidelberg and Tuebingen University Hospitals with metastatic breast cancer had a discordance of HR and HER2 status between their primary tumor and metastasis. Antiendocrine treatment and HER2-directed treatment changed in $20 \%$ and $14 \%$, respectively. As receptor conversion influences endocrine and HER2-directed therapy decision and significantly impacted OS these results are of high clinical relevance. Hence, in accordance with current guidelines, our results confirm that biopsy of metastatic tissue should be pursued wherever feasible.

Acknowledgements Open Access funding provided by Projekt DEAL. The authors gratefully thank all patients whose data were used in this study. We would also thank the medical and nursing staff at the National Center for Tumor Diseases (NCT; Heidelberg) and the Department of Obstetrics and Gynecology University Hospital Tuebingen for excellent management and care of our patients, the laboratory staff at the Department of Pathology in Heidelberg and Tuebingen, for excellent histopathological analysis.

Author contributions TMD, MW, ADH and AS jointly conceived the study and developed its design. ADH, MW and AS supervised the study. TMD, CE, JN, FS, CF, EMG, PS, SYB, AS, ADH and MW participated in patient recruitment, patient management, clinical data collection, sample collection, and sample analysis. VW, ChF, TMD and JN organized and reported the data, constructed the databases, and conducted data management. VW performed the statistical analysis. VW, ChF, TMD, ADH, and MW participated in data analysis and interpretation. $\mathrm{VW}, \mathrm{ChF}, \mathrm{TMD}, \mathrm{ADH}$ and $\mathrm{MW}$ drafted the manuscript. VW, ChF, TMD, CE, JN, FS, CF, EMG, PS, SYB, AS, ADH and MW critically revised the manuscript for important and gave important intellectual contribution. VW and ChF prepared the final manuscript. All authors read and approved the final manuscript.

Funding $\mathrm{CF}$ has received honoraria from Roche, Celgene, Pfizer and Amgen. AS reports grants from Celgene, grants from Roche, grants from AbbVie, grants from Molecular Partner, personal fees from Roche, personal fees from AstraZeneca, personal fees from Celgene, personal fees from Pfizer, personal fees from Novartis, personal fees from MSD, personal fees from Tesaro, personal fees from Lilly, other from Roche, outside the submitted work.

\section{Compliance with ethical standards}

Conflict of interest All other authors declare that they have no conflicts of interest.

Ethical approval All procedures carried out in studies with human participants complied with the ethical standards of the Institutional Research Committee (S-295/2009 and 270/2014A) and the 1964 Helsinki Declaration and their subsequent amendments or comparable ethical standards. This article does not include studies with animals carried out by any of the authors.

Informed consent Informed consent was obtained from all individual participants included in the study.

Open Access This article is licensed under a Creative Commons Attribution 4.0 International License, which permits use, sharing, adaptation, distribution and reproduction in any medium or format, as long as you give appropriate credit to the original author(s) and the source, provide a link to the Creative Commons licence, and indicate if changes were made. The images or other third party material in this article are included in the article's Creative Commons licence, unless indicated otherwise in a credit line to the material. If material is not included in the article's Creative Commons licence and your intended use is not permitted by statutory regulation or exceeds the permitted use, you will need to obtain permission directly from the copyright holder. To view a copy of this licence, visit http://creativecommons.org/licenses/by/4.0/.

\section{References}

1. Bray F, Ferlay J, Soerjomataram I et al (2018) Global cancer statistics 2018: GLOBOCAN estimates of incidence and mortality 
worldwide for 36 cancers in 185 countries. CA Cancer J Clin 68(6):394-424. https://doi.org/10.3322/caac.21492

2. Dafni U, Grimani I, Xyrafas A et al (2010) Fifteen-year trends in metastatic breast cancer survival in Greece. Breast Cancer Res Treat 119(3):621-631. https://doi.org/10.1007/s1054 9-009-0630-8

3. Chia SK, Speers CH, D'yachkova Y et al (2007) The impact of new chemotherapeutic and hormone agents on survival in a population-based cohort of women with metastatic breast cancer. Cancer 110(5):973-979. https://doi.org/10.1002/cncr.22867

4. Duffy MJ, Harbeck N, Nap M et al (2017) Clinical use of biomarkers in breast cancer: updated guidelines from the European group on tumor markers (EGTM). Eur J Cancer 75:284-298. https://doi.org/10.1016/j.ejca.2017.01.017

5. Harris LN, Ismaila N, McShane LM et al (2016) Use of biomarkers to guide decisions on adjuvant systemic therapy for women with early-stage invasive breast cancer: American society of clinical oncology clinical practice guideline. J Clin Oncol 34(10):1134-1150. https://doi.org/10.1200/JCO.2015.65.2289

6. Schrijver WAME, Suijkerbuijk KPM, van Gils CH et al (2018) Receptor conversion in distant breast cancer metastases: a systematic review and meta-analysis. J Natl Cancer Inst 110(6):568-580. https://doi.org/10.1093/jnci/djx273

7. Yeung C, Hilton J, Clemons M et al (2016) Estrogen, progesterone, and HER2/neu receptor discordance between primary and metastatic breast tumours-a review. Cancer Metastasis Rev 35(3):427-437. https://doi.org/10.1007/s10555-016-9631-3

8. Lindström LS, Karlsson E, Wilking UM et al (2012) Clinically used breast cancer markers such as estrogen receptor, progesterone receptor, and human epidermal growth factor receptor 2 are unstable throughout tumor progression. J Clin Oncol 30(21):2601-2608. https://doi.org/10.1200/JCO.2011.37.2482

9. Liedtke C, Broglio K, Moulder S et al (2009) Prognostic impact of discordance between triple-receptor measurements in primary and recurrent breast cancer. Ann Oncol 20(12):19531958. https://doi.org/10.1093/annonc/mdp263

10. National Comprehensive Cancer Network (NCCN). Breast Cancer (Version 1.2019) https://www.nccn.org/professionals/physi cian_gls/pdf/breast.pdf. Accessed 4 Apr 2019

11. Cardoso F, Senkus E, Costa A et al (2018) 4th ESO-ESMO international consensus guidelines for advanced breast cancer (ABC 4) †. Ann Oncol 29(8):1634-1657. https://doi. org/10.1093/annonc/mdy 192

12. Rugo HS, Rumble RB, Macrae E et al (2016) Endocrine therapy for hormone receptor-positive metastatic breast cancer: American society of clinical oncology guideline. J Clin Oncol 34(25):3069-3103. https://doi.org/10.1200/JCO.2016.67.1487

13. van Poznak C, Somerfield MR, Bast RC et al (2015) Use of biomarkers to guide decisions on systemic therapy for women with metastatic breast cancer: American society of clinical oncology clinical practice guideline. J Clin Oncol 33(24):2695-2704. https://doi.org/10.1200/JCO.2015.61.1459

14. Amir E, Miller N, Geddie W et al (2012) Prospective study evaluating the impact of tissue confirmation of metastatic disease in patients with breast cancer. J Clin Oncol 30(6):587-592. https://doi.org/10.1200/JCO.2010.33.5232

15. Wolff AC, Hammond MEH, Allison KH et al (2018) Human epidermal growth factor receptor 2 testing in breast cancer: American society of clinical oncology/college of American pathologists clinical practice guideline focused update. J Clin Oncol 36(20):2105-2122. https://doi.org/10.1200/JCO.2018.77.8738

16. Lindström LS, Yau C, Czene K et al (2018) Intratumor heterogeneity of the estrogen receptor and the long-term risk of fatal breast cancer. J Natl Cancer Inst 110(7):726-733. https://doi. org/10.1093/jnci/djx270
17. Niikura N, Liu J, Hayashi N et al (2012) Loss of human epidermal growth factor receptor 2 (HER2) expression in metastatic sites of HER2-overexpressing primary breast tumors. J Clin Oncol 30(6):593-599. https://doi.org/10.1200/ JCO.2010.33.8889

18. Karlsson E, Lindström LS, Wilking U et al (2010) Discordance in hormone receptor status in breast cancer during tumor progression. J Clin Oncol 28(15\suppl):1009. https://doi.org/10.1200/ jco.2010.28.15_suppl.1009

19. Dieci MV, Barbieri E, Piacentini F et al (2013) Discordance in receptor status between primary and recurrent breast cancer has a prognostic impact: a single-institution analysis. Ann Oncol 24(1):101-108. https://doi.org/10.1093/annonc/mds248

20. Hoefnagel LDC, Moelans CB, Meijer SL et al (2012) Prognostic value of estrogen receptor $\alpha$ and progesterone receptor conversion in distant breast cancer metastases. Cancer 118(20):4929-4935. https://doi.org/10.1002/cncr.27518

21. Kimbung S, Kovács A, Danielsson A et al (2015) Contrasting breast cancer molecular subtypes across serial tumor progression stages: biological and prognostic implications. Oncotarget 6(32):33306-33318. https://doi.org/10.18632/oncotarget.5089

22. Robertson S, Rönnlund C, de Boniface J et al (2019) Re-testing of predictive biomarkers on surgical breast cancer specimens is clinically relevant. Breast Cancer Res Treat 174(3):795-805. https ://doi.org/10.1007/s10549-018-05119-2

23. Meattini I, Bicchierai G, Saieva C et al (2017) Impact of molecular subtypes classification concordance between preoperative core needle biopsy and surgical specimen on early breast cancer management: single-institution experience and review of published literature. Eur J Surg Oncol 43(4):642-648. https://doi. org/10.1016/j.ejso.2016.10.025

24. Nakamura R, Yamamoto N, Shiina $N$ et al (2016) Impact of host and histopathological factors on the discrepancies in estrogen receptor, and progesterone receptor, and HER2 status between core needle biopsy and surgically excised tumors. Breast (Edinburgh, Scotland) 26:141-147. https://doi.org/10.1016/j.breas t.2015.10.009

25. Dekker TJA, Smit VTHBM, Hooijer GKJ et al (2013) Reliability of core needle biopsy for determining ER and HER2 status in breast cancer. Ann Oncol 24(4):931-937. https://doi.org/10.1093/ annonc/mds599

26. Li S, Yang X, Zhang Y et al (2012) Assessment accuracy of core needle biopsy for hormone receptors in breast cancer: a metaanalysis. Breast Cancer Res Treat 135(2):325-334. https://doi. org/10.1007/s10549-012-2063-Z

27. Arnedos M, Nerurkar A, Osin P et al (2009) Discordance between core needle biopsy $(\mathrm{CNB})$ and excisional biopsy (EB) for estrogen receptor (ER), progesterone receptor $(\mathrm{PgR})$ and HER2 status in early breast cancer (EBC). Ann Oncol 20(12):1948-1952. https ://doi.org/10.1093/annonc/mdp234

28. Pfitzner BM, Lederer B, Lindner J et al (2018) Clinical relevance and concordance of HER2 status in local and central testingan analysis of 1581 HER2-positive breast carcinomas over 12 years. Mod Pathol 31(4):607-615. https://doi.org/10.1038/modpa thol.2017.171

29. McCullough AE, Dell'orto P, Reinholz MM et al (2014) Central pathology laboratory review of HER 2 and ER in early breast cancer: an ALTTO trial BIG 2-06/NCCTG N063D (Alliance) ring study. Breast Cancer Res Treat 143(3):485-492. https://doi. org/10.1007/s 10549-013-2827-0

30. Dixon JM, Cameron DA, Arthur LM et al (2019) Accurate estrogen receptor quantification in patients with negative and low-positive estrogen-receptor-expressing breast tumors: sub-analyses of data from two clinical studies. Adv Ther 36(4):828-841. https:// doi.org/10.1007/s12325-019-0896-0 
31. Darvishian F, Singh B, Krauter S et al (2011) Impact of decalcification on receptor status in breast cancer. Breast J 17(6):689-691. https://doi.org/10.1111/j.1524-4741.2011.01168.x

32. Largillier R, Ferrero J-M, Doyen J et al (2008) Prognostic factors in 1038 women with metastatic breast cancer. Ann Oncol 19(12):2012-2019. https://doi.org/10.1093/annonc/mdn424

33. Chung W, Eum HH, Lee H-O et al (2017) Single-cell RNAseq enables comprehensive tumour and immune cell profiling in primary breast cancer. Nat Commun 8:15081. https://doi. org/10.1038/ncomms 15081

34. Wang Y, Waters J, Leung ML et al (2014) Clonal evolution in breast cancer revealed by single nucleus genome sequencing. Nature 512(7513):155. https://doi.org/10.1038/nature13600

35. Nik-Zainal S, van Loo P, Wedge DC et al (2012) The life history of 21 breast cancers. Cell 149(5):994-1007. https://doi. org/10.1016/j.cell.2012.04.023

36. Shah SP, Morin RD, Khattra J et al (2009) Mutational evolution in a lobular breast tumour profiled at single nucleotide resolution. Nature 461(7265):809-813. https://doi.org/10.1038/nature08489

37. Macfarlane R, Seal M, Speers C et al (2012) Molecular alterations between the primary breast cancer and the subsequent locoregional/metastatic tumor. Oncologist 17(2):172-178. https://doi. org/10.1634/theoncologist.2011-0127

38. Paoletti C, Muñiz MC, Thomas DG et al (2015) Development of circulating tumor cell-endocrine therapy index in patients with hormone receptor-positive breast cancer. Clin Cancer Res 21(11):2487-2498. https://doi.org/10.1158/1078-0432. CCR-14-1913

39. Dawson S-J, Tsui DWY, Murtaza M et al (2013) Analysis of circulating tumor DNA to monitor metastatic breast cancer. New Engl J Med 368(13):1199-1209. https://doi.org/10.1056/NEJMoa1213261

40. Alix-Panabières C, Pantel K (2016) Clinical applications of circulating tumor cells and circulating tumor DNA as liquid biopsy. Cancer Discov 6:479
41. Bidard F-C, Proudhon C, Pierga J-Y (2016) Circulating tumor cells in breast cancer. Mol Oncol 10(3):418-430. https://doi. org/10.1016/j.molonc.2016.01.001

42. Diaz LA, Bardelli A (2014) Liquid biopsies: genotyping circulating tumor DNA. J Clin Oncol 32(6):579-586. https://doi. org/10.1200/JCO.2012.45.2011

43. Amir E, Clemons M, Purdie CA et al (2012) Tissue confirmation of disease recurrence in breast cancer patients: pooled analysis of multi-centre, multi-disciplinary prospective studies. Cancer Treat Rev 38(6):708-714. https://doi.org/10.1016/j.ctrv.2011.11.006

44. Curigliano G, Bagnardi V, Viale G et al (2011) Should liver metastases of breast cancer be biopsied to improve treatment choice? Ann Oncol 22(10):2227-2233. https://doi.org/10.1093/ annonc/mdq751

45. Simmons C, Miller N, Geddie W et al (2009) Does confirmatory tumor biopsy alter the management of breast cancer patients with distant metastases? Ann Oncol 20(9):1499-1504. https://doi. org/10.1093/annonc/mdp028

46. Thompson AM, Jordan LB, Quinlan P et al (2010) Prospective comparison of switches in biomarker status between primary and recurrent breast cancer: the breast recurrence in tissues study (BRITS). Breast Cancer Res 12(6):R92. https://doi.org/10.1186/ bcr2771

47. Sperduto PW, Mesko S, Li J et al (2020) Estrogen, progesterone and her2 receptor discordance between primary tumor and brain metastases in breast cancer and its effect on treatment and survival. Neuro-Oncology. https://doi.org/10.1093/neuonc/noaa025

48. Untch M, Jackisch C, Thomssen C et al. (2006) Adjuvante Therapie mit Trastuzumab bei Mammakarzinompatientinnen. Dtsch Arztebl International 103(50):A-3406-

Publisher's Note Springer Nature remains neutral with regard to jurisdictional claims in published maps and institutional affiliations.

\section{Affiliations}

\section{Vincent Walter ${ }^{1}$. Chiara Fischer ${ }^{2,3} \cdot$ Thomas M. Deutsch $^{2,3}$. Catherine Ersing ${ }^{1}$. Juliane Nees ${ }^{2}$. Florian Schütz ${ }^{2}$. Carlo Fremd $^{3}$. Eva-Maria Grischke ${ }^{1}$. Peter Sinn ${ }^{5}$. Sara Y. Brucker ${ }^{1} \cdot$ Andreas Schneeweiss $^{3,4}$. Andreas D. Hartkopf ${ }^{1}$. Markus Wallwiener ${ }^{2}$ (D)}

Vincent Walter

Vincent.Walter@med.uni-tuebingen.de

Chiara Fischer

Chiara.Fischer@stud.uni-heidelberg.de

Thomas M. Deutsch

Thomas.Deutsch@med.uni-heidelberg.de

Catherine Ersing

Catherine.Ersing@student.uni-tuebingen.de

Juliane Nees

Juliane.Nees@med.uni-heidelberg.de

Florian Schütz

Florian.Schuetz@med.uni-heidelberg.de

Carlo Fremd

Carlo.Fremd@med.uni-heidelberg.de

Eva-Maria Grischke

Eva-Maria.Grischke@med.uni-tuebingen.de

Peter Sinn

Peter.Sinn@med.uni-heidelberg.de
Sara Y. Brucker

Sara.Brucker@med.uni-tuebingen.de

Andreas Schneeweiss

Andreas.Schneeweiss@med.uni-heidelberg.de

Andreas D. Hartkopf

Andreas.Hartkopf@med.uni-tuebingen.de

1 Department of Obstetrics and Gynecology, University Hospital Tuebingen, Calwerstraße 7, 72076 Tuebingen, Germany

2 Department of Obstetrics and Gynecology, University Hospital Heidelberg, Im Neuenheimer Feld 440, 69120 Heidelberg, Germany

3 Division of Gynecologic Oncology, National Center for Tumor Diseases (NCT), Im Neuenheimer Feld 460, 69120 Heidelberg, Germany

4 German Cancer Research Center, Im Neuenheimer Feld 280, 69120 Heidelberg, Germany

5 Department of Pathology, University Hospital Heidelberg, Im Neuenheimer Feld 224, 69120 Heidelberg, Germany 